\title{
This Moment, Back then: retro imaginary, nostalgia and memories in contemporary Taiwan visual culture
}

\author{
par Corrado Neri
}

\begin{abstract}
Many recent, successful - in terms of selling, but also in terms of diffusion and international visibility - works of Taiwanese popular culture dwell in a problematic form of nostalgia. This paper will contextualise and analyse two films that confirm the "retro-trend" in 2015 and 2016, each of them resonating with a diffuse nostalgic atmosphere: Wo de shaonü shidai/Our Times (Chen, 2015) and Nashi cike/The Moment (Yang, 2016). The former is a fiction film situated in the nighties; the latter - which is accompanied by a book by the same author published the same year - is a documentary celebrating the 50s anniversary of Golden Horse Film Festival. While engaging different forms of retro imaginary, compelling the spectators to go back to Taiwan recent past, asking audience to read the "past within us" and evaluating the representation's "truthfulness to history", these films engage a specific form of historiographical thinking. Our Times and The Moment are powerful nostalgia inducing contemporary movies that enhance dramatically the contemporary construction of a "taiwanesness" (a collective memory, a common experience) based on personal memory and shared cultural experience - and their specific combination in the perception of contemporary spectators.
\end{abstract}

Keywords: Taiwan cinema, Documentary, Nostalgia, Golden Horse Film Festival.

\section{Résumé}

De nombreuses œuvres récentes et réussies (tant du point de vue des recettes commerciales, que de la diffusion et de la visibilité internationale) de la culture populaire taïwanaise expriment une forme problématique de nostalgie. Cet article contextualisera et analysera deux films qui confirment la " tendance rétro » actuelle ; chacun d'entre eux se faisant l'écho d'une atmosphère nostalgique diffuse : Wo de shaonü shidai / Our Times (Chen, 2015) et Nashi cike / The Moment (Yang, 2016). Le premier est un film de fiction situé dans les années 1980 : accompagné d'un livre du même auteur publié la même année, il s'agit d'un documentaire célébrant les 50 ans du Festival 
du film Golden Horse. Tout en étant liés à différentes formes de rétro imaginaire, en obligeant les spectateurs à revenir au passé récent de Taiwan, en demandant au public de lire le "passé en nous » et en évaluant la "véracité de de la représentation de l'histoire ", ces films relèvent d'une forme spécifique de pensée historiographique. Our Times et The Moment traduisent la puissante nostalgie induisant présente dans les films contemporains qui renforcent de façon spectaculaire la construction contemporaine d'un « être taïwanais » (une mémoire collective, une expérience commune) basée sur la mémoire personnelle, une expérience culturelle partagée et leur combinaison singulière dans la perception des spectateurs contemporains.

Mots-clés : Cinéma taiwanais, Documentaire, Nostalgie, Festival du film Golden Horse.

\section{Overwhelmed by the past}

In recent years a nostalgia (huaijiu) mood has overwhelmed many cultural products in Taiwan: the quantity of nostalgic expressions for the recent past, and the enthusiastic response they invariably arouse make the retro mania (or vintage attitude) one of the most important aesthetic trend of the years 2000. Graphic novels like Sean Chuang's or Huang Shengwen generational autobiographies 80s Diary in Taiwan ${ }^{1}$ and Those Years, ${ }^{2}$ books by Wu Ming-yi like The Illusionist on Skywalk and other short stories, ${ }^{3}$ as well as films like Junzhong leyuan/Paradise in Service (Niu, 2014), Mengjia/ Monga (Niu, 2010), Nanian, women yiqi zhui de nühai/You are the Apple of My Eye (Ke - aka Giddens Ko -, 2011), Jiong nanhai/ORZ Boys (Yang, 2008), Nüpengyou/Nanpengyou/GF/BF (Yang, 2012), Bian shen/Machi Action (Zhang, 2012), Fangun ba! Ahxin/Jump! Ashin (Lin, 2011), Wo de shaonü shidai/Our Times (Chen, 2015) and Nashi cike/The Moment (Yang, 2016), TV series like Shiliu ge xiatian/The Way We Were (2014) recreate, revise, quote and celebrate the specificities of Taiwan experience. And they all, each with its own language and focus, invariably underline how the present is rich and free, but the past was more meaningful and intense.

Since I discussed elsewhere 4 in a more comprehensive way the huge mass of nostalgic products that overwhelm Taiwan market, I'll concentrate in the following pages on two films that confirm the "retro-trend" in 2015 and 2016, each of them resonating with a diffuse nostalgic atmosphere: Our Times and The Moment. The former is a fiction film situated in the nighties; the latter - which is accompanied by a book by the same author published the same year - is a documentary celebrating the 50s anniversary of Golden Horse Film Festival. They engage two different forms of retro imaginary, the first one by the means of a fictional reconstruction of the past, the second by presenting images of classic movies. Nonetheless, they are both powerful nostalgia inducing contemporary movies that enhance dramatically the contemporary construction of a "taiwanesness" (a collective memory, a common experience) based on personal memory and shared cultural experience - and their specific combination in the perception of contemporary spectators. They both are, as we shall see, part of an established tradition of retro movies, a subgenre of historical film that can be, according to Robert Rosenstone, ${ }^{5}$ a legitimate form of historiography that, via the creation of visual metaphors, can help present day spectator to "think historically". 


\section{Huaijiu, retro, vintage}

Sometimes this nostalgic attitude is explicit, as in Those Years (a splendid book designed as a collection of vintage film frame), which ends with a lush celebration of contemporary Taiwan where "anyone can do, eat, buy and say what he or she wants", "go wherever one desires"... but dedicates the last images portraying a child watching the world through a marble; he sees images of the 60s and 70s in Taiwan, and the author concludes "remembering that shitty period fills my heart with warmth". Paradoxically (but very understandably) nostalgia works even when the author recognise the social and political progress of the country: what is at stake here is a constructed vision of a "pure", innocent, simpler life where the scarcity of consumerist goods made experiences more intense. More often the nostalgic attitude is perceptible via visual stimulation, as in films like GF/ $B F$, where the formation years are shot through a palette of bright, saturated colours that channel enthusiasm and sexiness, while on the contrary adult age is filmed in dim lights, shades of grey, Apple store-like settings, that tell the material success of the protagonist and their inner despair and alienation of contemporary world.

The definitions of "retro" and "vintage" are often imprecise, partly because they are relative: it depends on when they "retro mania" is manifested. I would say, following Reynolds ${ }^{6}$ and Guffey, that "retro" has a more diffuse sense, linked to cultural phenomena; while "vintage" has a connotation linked to commodification and consumer practices. Even without clear-cut definition, one metaphor suffices to very clearly pinpoint the object of our research: the gesture of watching in the rear-view mirror. While driving ahead (direction of the narration and, supposedly, of history) we keep seeing something behind us, still lingering in our field of vision, but gone already. This visual allegory aptly defines a field of vision and an attitude, no matter if applied to Taiwan or the West (which, needless to say, is not a monad either).

The "retro-imaginary" create a nostalgia for something lost that can retrospectively sound more alluring (or, simply, "real") than the virtual capitalistic world we are immerged in. The "vintage-mania" tells of an anxiety towards a fast-changing world where the all-disposable, all-immediate can both enrich (immensity of database, access to immaterial resources, global indexisation) but also impoverish the contemporary imaginary and desiccate the ideological drive (lack of ideals, desegregation of myths). The obsession - rediscovery - for a specific, local, unique cultural experience is also evident in the touristic exploitation and restoration of ancient buildings, streets, as well as restaurants and shops. Terms like huaijiu ("nostalgia") or fugu ("restaure ancient ways") - just to name a few examples - are wildly used in the recently (2014) reopened Hayashi shopping mall in Tainan, where visitors cue up to use the almost one century old elevator that used to be the pride of the then ultramodern building; maps are drawn for the tourist to dwell in the "ancient" markets of Taipei or Gaoxiong in search of an authentic flavour of tradition, and restaurants recreate the time past dressing up waiters in the uniform of past days postmen, letting clients sit on school benches, or display on the wall ancient movie posters or vinyl albums. So, if nostalgia is as old as human kind, nostalgia for a pre-Internet period is specific of the year 2000s, and nostalgia for the progressive and struggling time from martial law to post martial law epoch, is specific to Taiwan. The importance of nostalgia today can be linked to the obsessive research and recreation of national identity by new generations of Taiwanese.

Some tentative, preliminary interpretations of the recurrence of the retro-imaginary are related to notions of anxiety of assimilation in a globalized reality and a political retrospective gaze in 
search of an (imaginary?) definition of cultural (if not political) identity. The generation of fathers, the immediate past, the already gone but still lingering... can create the illusion of a precise, definable (chauvinist?) national reality and specificity in contrast with the blurring of capitalist frenzy that seems to make all pillars melt away, to produce recurrent amnesia and to erase of historical memories and consciousness. "Retro-imaginary" stands in between the virtually infinite archive at disposition of anyone and its fast consumption; between the possibility of collecting images, sounds and videos related to recent history and the recurrent alarm about the end of ideology and values that supposedly structured the last era, questioning the interface between the deep legacies of fathers and the hyper-connected Internet globalized surface.

Here we can grasp two different qualities of "retro imaginary", which will be negotiated case by case by the authors of films and by the spectators who read them. Some vintage products are accused of being conservative and create a false, stereotyped memory of the past, indulging in packaged nostalgia, while refraining from a serious, critical study. Other voices claim the possibility of retro as resistance to present-day fast consumption society. Hartmut Rosa, ${ }^{8}$ for instance, talks about the perceived speed of contemporary society, and the consequent need for "de-synchronisation". These decelerations are forms of resistance that demand to eat "slow", to walk instead then drive cars, to moderate the pace, and to appreciate the laborious stages of production - including the production of collective identity, hence the possibility that even consumer-driven films could contain forms of counter power, or at least of challenge vis-à-vis capitalist self-devouring struggle of contemporary world.

In a moment where the self-definition as Taiwanese seems less and less problematic, less and less subject to controversy (at least, on the island), looking back at the formation years of Taiwan actual democratic system and international isolation is a way to propose an assertive, yet less (compared to New Cinema modernism) formally challenging definition(s) of cultural and collective identity. Contemporary Retro-texts underline a specific taiwaneseness expressed via a globalised commercial language, as we'll see in the following pages. We are not anymore in a New Cinema context - Hou Hsiao-hsien and his peers - that provided highly original forms to decipher Taiwan past and culture. If retro imaginary can be accused of not creating a challenging, original cinematographic language, on the other hand the proliferation of these films in contemporary culture can also hint of the advent of a community that had struggled to be imagined as a nation both by Taiwanese themselves and by non-Chinese. ${ }^{9}$ Retro films tell of a common experience that is more uniform and less contrasted and contradictory compared to the 60s and 70s: we are talking of a generation, who grown up during the 80s and 90s, that has similar cultural background, where the struggle between waishengren (Chinese arrived after 1949), bendiren (local natives, lived under the Japanese rule) and yuanzhuming (aboriginal people, historically oppressed by all regimes, gradually gaining voice and agency) is less accentuated. It's a generation that shares a "Taiwan experience", made certainly of contrasts (class, income, gender etc.), but also of common possibilities, common negotiation with an established, post-martial law system of values, and a common consumption of transcultural products in a resolutely globalized context. This community shares also the imposed "sinisation" of the martial law period; this apparent contradiction ceases to be one if we bear in mind that the (certainly created) tradition of Chinese past and heritage has been imposed while the mainland was in the process of battling all remnants of Confucian tradition during the cultural revolution.

Even more important: the simple (yet not given elsewhere) possibility to discuss this recent past: unlike other Chinese speaking realities, it is possible to publicly debate about sensitive historical 
pages like the White Terror, the propaganda movies or pro-democracy movement in contemporary productions; this is a Taiwanese specificity, regardless if in its artistic expression, this claim for Taiwanese specificity remains more or less implicit

As demonstrated by the incomplete list compiled before, the "nostalgia factory" (which is time itself" according to the evocative text of Douwe Draaisma ${ }^{10}$ is working at full capacity in the Taiwanese context, but I need first to clarify that I do not intend to stress a supposedly unique characteristic of Taiwan culture, or a specificity of "Taiwanese thinking". Things related to yearnings and nostalgia, commonplaces on time past and remembrances, questions about past generation's experience and the importance of memories are timeless and universal (nihil sub sole novum). What makes it relevant in Taiwan today is their content, the sheer, adamant and simple fact that a large number of successful contemporary popular texts revise, celebrate, recreate Taiwan's own past in a "inward push" that can be perceived as both a conservative, paralyzed self-celebration, or a progressive attitude cementing a local identity, therefore a specificity defying global standardisation and more urgently, Mainland Chinese economic and cultural assimilation. All these texts display a very focused interest in local memories and cultural production; consequently, if the Walkman is a 1980s ubiquitous sign, the passage from martial law to democratic system while suffering diplomatic isolation, is a very specific Taiwan characteristic. If the switch from celluloid to digital cinema is universal, the celebration of Golden Horse Film Festival and Taiwan New Cinema are ways of celebrate unique forms of "Taiwanesness".

\section{I, We, Our}

As mentioned before, I'll focus on two texts (and their context): the fiction film Our Times and the documentary The Moment. Two and a half, actually: The Moment consists in a sort of double instalment, since a documentary film and a non-fiction book by the same author were published/ released in a few weeks interval in 2016 and serve as complementary texts (more sooner). Both these texts have a parallel: Our Times (box office hit of 2015 first in Taiwan, then in China) is a reproduction of the box office hit You are the Apple of my Eyes; this last one tells a very similar story, but declined in a masculine perspective, while the latter is dedicated to the female protagonist, and the director assures that the story comes in part from her biography. (The Moment has been preceded by another documentary, Guanyin de gushi/Flowers of Taipei (Hsieh, 2014), which we'll discuss later, and that has similar, self-celebrating tones.) The fact that one is a documentary and the other is a fiction feature shouldn't bother the reader: if their language is different, they enter in the same pattern of self-celebrating nostalgia, of construction of shared identity, of community building that reflects contemporary contradictory assertiveness and on-going search, mirrored by 2016 political change - Tsai Ying-wen of DDP claiming victory after two Nationalist mandates.

As all case study, the present one implies exclusion and inclusions stemming from personal choices: these texts are, in my eyes, particular representative of the retro style, there are numerous cross-references among them, they are recent (2015 and 2016) but come from a decade long trend. They indeed produce different kind of nostalgia: diffuse atmosphere vs. historical narrative. I argue that both works are effective because they resonate with the Zeitgeist, which imposes or demands to create an emotional form of cinema, very far from the cold, more intellectual, hard to decipher experimentation of Taiwan New Cinema. While Taiwan New Cinema has been extremely influent in the international scene, but progressively lost its local audience, scattered movies - like Our 
times - appeal to the local taste which gives them a warm result in terms of box office revenue, proof of a public interest in nostalgia-ridden cultural texts. Books/DVD of Flowers of Taipei and The Moment are on all bookshelves, telling us about the necessity, desire and pleasure of the public in dwelling in retro emotional nostalgia - as in contrast with "cold", intellectual, experimental language of New Cinema. It's interesting to note that Our Times has been successful on the Mainland as well. Hypothesis: the Chinese public can't possibly share these memories, but might be sutured into history but the "prosthetic memory", a form of collective memory disseminated, circulated and transformed by media. ${ }^{11}$ The Chinese public and industry were eager to appropriate icons and styles (such as Teresa Tang or Andy Lau) that didn't belong to the end of the Cultural Revolution or the beginning of the Deng era, but at the same time were speaking the same language, referring to communal shared values, titillating a collective imaginary eager to catch up with the capitalist world. In other terms, the past represented in these nostalgic movies is a form of wishful memory that mainland public is keen to appropriate - to build on it the actual high-speed consumerist society that yet needs form of "tradition". Hence, we assist to the comeback of wuxiapian, of ghost movies, of opera and theatre canons, all sustained by the reiterated call to the plurimillennial Chinese civilisation.

Symbolically, Our Times and The Moment share a term in their Chinese title, which is not a coincidence: the personal possessive adjective. In other words, they celebrate a common "taiwanesness", shared between them and their public. In the case of Our Times the English title obviously refers to the construction of a generational identity. The title Our Times can also be seen as a reference to the founding collective film of Taiwan New Cinema, aptly called In Our Time (1982). The Chinese title is, on the other hand, "Wo de shaonü shidai", that can be translated as "the Time of my teenage years", or "When I was a teenage girl", so the narrative point of view is specified as being the one of the female protagonist. The subjective "I" become generational plural.

The Moment's Chinese title is "Na shi cike - women de nashi cike", which includes many different possible translation, like "we... back then, we... at this moment" hinting at the coexistence and presence of two different timelines, past and present, present into past, and the "We" encompassing them both, or framing, or witnessing, or possessing, or bearing a double timeline. The collective "we" become gauge of continuity from past to present.

They both link specific inward gaze (material culture for the former, film classic for the latter) with a generational collective memory that is relevant in a discussion of the present; the fact that they appeal to a large public urge a comparative analysis.

In both cases, we are not speaking about an imaginary "Chinese" culture stretching through millennia: set, light and cloths designers dwell in a "retro-mood", "vintage universe", a diffuse collective memory, a modest but weighty feeling of collective, shared memories - very different, we can see, from the recollection of the imperial past promoted by the classics films made in Taiwan by Li Hanxiang (1926-1996) or King Hu (1932-1987) who celebrated the essence of a Chinese culture deemed lost in the continent, a culture that survives in the "only" China, the Nationalist Party ruled Taiwan or, even more paradoxically, the British colony of Hong Kong. We are in a globalized reality, where Taiwan is interfacing with the rest of the word: cultural actors and consumers have to face the new experiences of digitalization, of apparently infinite database index, and of dematerialization of cultural objects - including books, music, films and TV shows from Mad Men to Star Wars, from the works of Michel Gondry, J. J. Abrams or Spike Jonze to the music of Daft Punk. 
Our Times and The Moment both display a very classic, readable, globalised standard cinematic language, without asperities: linear montage, clear storylines, chapter division, beginning-climax-end, and emotional orchestra background music. At a content level, they dwell in the depth of local popular culture, reminding present-day Taiwanese public the cradle of current reality and the necessity of self-reflexion. This "Taiwanese identity" is understandably plural (as elsewhere); but in both cases, it identifies plurality as a distance from Mainland China and a Taiwanese specificity - to be cherished or critiqued, but never to be erased.

\section{Our Times: Retro as an opportunity for history}

Our Times is a fiction film often categorized as an "idol" movie: pretty faces falling in love in a high school context during the 90s. The film opens with the female protagonist who has to suffer, in contemporary Taipei, unsatisfactory work conditions (she is an office lady) and an unfulfilling couple life. She then goes back with memory to the high school days, and the movie recalls her falling in love with the best-looking boy of the promotion, her contrasted friendship with the bad boy (who she will finally discover being her true love), the friendship's ebbs and flows, the tense relationships with stubborn and reactionary teachers, and generally a recreation of the days before the Internet.

In terms of mise en scène, Our Times does not offer a specific, original, compelling style - as Tsai Ming-liang or Hou Hsiao-hsien's works do - that demands interpretation, or that offers a tribune for critical debate about hidden meanings, highbrow cultural tradition or authorship. What we find instead are fast pace, narrative montage and clear storytelling, beautiful actors - "idols" in the perfect Taiwanese TV style -, dramatic moments cut with comical reliefs, catchy music score and so on. To summarize: an uneventful, predictable, professionally shot youth feel good comedy. The local box-office success, that continues the positive trend set by nostalgic retro movies like $G F / B F$ or You are the Apple of my Eyes, seems to largely depend on the ability to reproduce the epoch, its atmosphere and its details, underlining the historical (community building) significance of this kind of film. Wang Nianying, ${ }^{12}$ for example, extensively reports the painstakingly work of collecting elements of the visual and material culture of two decades ago, including clothes, motorbikes and cars, posters and books, even the fast food chain goblets and packaging. Wang devote a particular interest to the research and purchase on the Internet of 90s memorabilia like the figurines and stickers and fan books and even a life size scale image of Andy Lau displayed in a record shop.

\section{Andy Lau as a living sign of collective identity}

The iconic figure of Andy Lau is of particular importance in the film narration (and in the sinophone linking of contemporary Taiwan culture). The young heroine is a long-time fan; she collects images and derived products, but never manages to buy a ticket for her favourite star's concerts. Until the very end: she's a grown up woman, still couldn't buy a place for Lau's concert, performing in Taipei. With a predictable coincidence, she meets Lau himself, jogging at the park, and the very night - melodramatic closure of the entire film - her long lost first love happens to work for the star. The reunited couple can finally attend to the concert and presumably realise their dream of young love, after having passed through the stages of grief, disillusionment, difficulties in the work field, aka the growing up process that demands to aim for more realistic goals and accept 
limitations, but also to never give up an healthy fighting spirit. Here Lau can be perceived as a sign of memory resistance vis-à-vis the "mainlandisation" of contemporary popular culture. Even though Lau is working in China, and - as we have seen - Our Times has been successfully distributed in China, yet the Hong Kong connection of his aura is undeniable. Via the stereotyped discourse of a conventional narration, I suggest that the recurrent presence of Hong Kong idol in retro movie hints at the definition of a pan Asian, sinophone culture that resist, or simply differentiate itself from communist China. The very development of genre films (horror, romantic comedies, action and the likes), often coproduced between Taiwan and Hong Kong, was a specific cultural trait that was conspicuously absent in the mainland till the 90s. In appropriating iconic image like Lau's, Our Time develop the same strategy as its antecedents (You are the Apple of my Eyes, Jump! Ashin and the like) in respect to Bruce Lee's myth. It's a statement of appropriation and of reconnaissance where powerful, iconic pop culture icons are described as a part of everyday life pattern. These recurrent appropriations say: Taiwan is and was, since long time, part of global, capitalist, modern world. This connection is an important part of Taiwan identity, made of combinations that become specificities, and help quench the thirst for self-definition of present-day audience.

The iconic images of Lau are diffused and recurrent all along Our Times, but there are many other different objects and situations that help recreate a sense of vintage past, where the spectator is invited to dwell: clothes, tapes, socializing habits (roller-skating, romantic RDV in fast food chain...), bubble tea and different brands of snacks and soft drinks, motorbikes and cars... Wang Nianying's article underscores the importance for director Chen Yushan of letting contemporary public understand what "bu fangbian (inconvenient)" means: the absence of cell phone and computer seems quite incomprehensible today, but she insisted in letting younger generation grasp the romance of waiting for hours in front of a phone, the attraction of a handwritten note, or the suspension of not knowing who send the chain letter, or who just used the pager to establish a contact. This immersion is, according to Chen, the most important aim of the film; she underlines how past generations had to struggle for self-identification and self-improvement, and how this struggle, though hard to grasp today, involved the forging of a fierce character, that may be missing today. The final chapter of Wang's long article (subtitled "Wo de shaonü shidai jieshu, er ' wo' zheng yao kaishi", "Where Our Times ends, "I" begin") focuses on the public who has the same age of the protagonists - late 30s/early 40s in 2015. The article closes in a very telling way, further shifting the attention from the fiction of the film to the construction of today's citizen's identity. Wang, acknowledging Chen's intention, admit that at the end of the movie many spectators might feel the urge to flip ancient school photo books, or check on the FB the status of their first love, or whatever happened to long time forgotten schoolmates. The questions are referred here only to a personal level: did « we » (the public) realised our full potential? How much did we compromise, what happened of youth ideals and dreams? This personal self-recognition level can easily shift to a political identity level, being a metaphor of today Taiwan's self-search. We found in the article and (implicitly) in the movie itself, the call for a collective writing of history, for a rejuvenation of definition of identity and community belonging. This consensus is built through commercial movies that use a retro imaginary, an imaginary field that includes historic threads as the development of a democratic, post-martial law consumerist culture, an open and multicultural consumerist reality (where, for example, FB is an actuality and not a forbidden foreign social network).

Marc Ferro urges to read a historic film for what it says but also (maybe: especially) for what it refrains to say, looking for the Freudian slip that can help the scholar to formulate a diagnosis, analysing the "ideological and social zones" that have been suppressed. ${ }^{13}$ We might then see under 
the surface of a pathos-numbed film the "call to arms" to build or rebuild the consciousness of the multiplicity of a specific Taiwan contemporary identity, contesting both global trends and continental drives. Even if Taiwan contemporary cinema industry can resist neither the sirens of China (in terms of distribution and production), nor the international, Hollywood-style pattern of narration, there will still be voices establishing, rekindling and revamping what made Taiwan arguably unique - its unique historical experience. Therefore: behind the readable immediate pleasure of nostalgia for youth, even these commercial retro films (and their success) can implicitly tell us of the necessity to defend the specificity of Taiwan contested identity.

Is Our Times nostalgia a purely commercial and consolatory strategy? Or might it offer a more discreet, problematic take on history and contemporary society? The chapter in the book version of The Moment dedicated to Our Times tries to answer to this question.

\section{Detour: Flowers of Taipei, or the confusion of "our times"}

I concentrate on The Moment because of its close contemporaneity with Our Times, and because Yang discusses Our Times in his book, but it is important to contextualise this film in a larger frame: the retrospective/celebratory/emotive format is in fact frequent in contemporary Taiwanese culture. A recent example is Guanyin de gushi/Flowers of Taipei, a similar "product" composed by a documentary film and a book. ${ }^{14}$ Flowers of Taipei was shown in Venice Film Festival in 2014; it celebrates the legacy of Taiwan New Cinema, presenting its more important directors (Hou Hsiaohsien, Yang Dechang...). The Chinese Title, Guanyin de gushi, is the same as the portmanteau film that started the New Cinema Movement in 1982 and that is translated in English as... In Our Time. Not to be confused with Our Times; but yet, the obsessive return of the same titles and personal pronouns (as we have seen, in The Moment Chinese title we found "Our" as well) can't be a coincidence and invite, on the contrary, to comparison. We are witnessing an inward push of Taiwan Cinema, a drive to self-reflection and auto celebration, the proud but somehow desperate call to emotion-ridden, melodramatic, emphatic assessment of local culture and heritage. The return of personal nouns ("our") reveals the necessity of appropriating and affirming a local, specific, glorious identity forged during moments of crisis. The DVD edition of Flowers of Taipei was accompanied (or the other way round) by a 300 pages book that extended the scope and depth of analysis of the filmic text. Tellingly enough, the book doesn't reproduce the film title, Flowers of Taipei, but manifest an uncanny return of the personal pronoun: Film in our Time. The specificity of Flowers of Taipei and Film in our Time is to present the witnesses - in form of interviews - of world directors, producers, and scholars recalling the influence of Taiwanese works on their own: Apichatpong Weerasethakul pays homage to the early works of Hou Hsiao-hsien, Olivier Assayas and Michel Frodon discuss the link between cinema and politics, Kore-Eda links the images of Taiwan New Cinema with the recollections of his own father, who was born and raised in South Taiwan... - just to mention few examples. It's a direct homage to the language, the formal innovations, the overall atmosphere of the legendary movement of New Cinema that blossomed during the 80s: there is the excitement of the discovery, the sense of an always expanding world cinema community, and the homage to past masters. Similar to The Moment, even if discussing different periods of time, Flowers is a work of nostalgic cinephilia and an emotional document on the power of cinema as political and philosophical enlightenment transcending national barriers. As well as a celebration of Taiwan soft power. 


\section{The Moment: cinematographic memories}

In the battlefield of sinophone movies, the Golden Horse Film Festival has been the principal agent in the cinematic soft power war for decades. The Moment, produced by the Golden Horse Film Festival describes the creation of the Festival as a celebration of ROC's cinema, and shows impressive newsreel images of the 50s and 60s Taiwan, intercut with sequences of classic fiction films - these iconic sequences (cinema itself) becomes here the retro "object" reconstructed and contextualised for the contemporary public gaze. In the second part, The Moment presents a pretty classic history of Taiwanese movies showing sequences (and the talking heads of directors, producers, actors) of Healthy Realism productions, New Taiwan Cinema success story from the 80s, and "Haijiao qihao/Cape $n^{\circ} 7$ (Wei, 2008) box office breakthrough.

The Moment/book ${ }^{15}$ follows the same chronological order but chooses to focus on a dozen of representative movies, from Liang Shangbo yu Zhuyingtai/Love Eterne (Li, 1963) to... Our Times! In a reference nostalgic loop, Yang acknowledges the overwhelming presence of retro-movies discussing the biggest box-office success of 2015, Our Times; and concludes the book by presenting his own film, The Moment, another retro-film, that celebrates the heritage and memory of Taiwanese cinema. The two and half texts (The Moment book + film, Our Times) overlap in the reproduction, self-breeding, and close system of the definition of a Taiwan specificity that keeps looking at its own past. They represent both the richness and frailty of the retro mania: multiplicity of point of view and "taiwanesness" construction (fiction and history; citation and pastiche; parody and homage), but also a self-referential system that seems obsessed with its own celebration.

The Moment (film) is an official representation of Taiwanese National cinema struggle to obtain recognition, to resist to political challenge, and to propose a different (as compared to mainland China) sinophone cinema. The movie unabashedly uses a form of cultural nationalism to discuss the struggle of Taiwan film production, and clearly aims to arouse emotion in a melodramatic way. The final sequence is composed of dozens of celebrities - actors (including Andy Lau), directors and producers - looking at the camera and thanking the public for sustaining the effort of the industry, striving to create a connivance between spectator and artists, both creators of collective culture and identity. The very catch phrase on the movie poster of The Moment promises "Endless emotion! (Wujin gandong)". In this prevarication of emotion over reflexivity we could see a major shift from the reflexive and distant approach of classic New Cinema products (the fiction by Hou, or the docu-fiction by Huang Ming-chuan, for instance).

Being highly emotional itself, The Moment nonetheless shows the direct impact of state propaganda in many sequences, the most important being the one when three retired soldiers are re-watching on a computer screen the propaganda classic Meihua/Victory (Liu, 1976). They recall how the film used to be source of inspiration for them to join the army; they evoke how their patriotic sentiments used to be aroused by this genre of film produced after the diplomatic setbacks of the 70s. One of them, drying up his tears, can't help but ask himself whatever happened to contemporary youth, who - unaware of the struggle of their parents - just seemed to have lost all ideals and noble causes to fight for. The Moment (book and film) texts seem apparently contradictory: the former discusses Our Times and criticize excessive and formulaic nostalgia as a form of conservative retreat into an imagined past, while the latter celebrates the classics from the past (without concealing their political agenda) stressing the emotional effect of the local success story. 


\section{Andy Lau as a sign of resistance}

Yet, some images of The Moment can be read as forms of resistance which may help make sense of this apparent contradiction. The Moment retro-compilation is a form of "de-synchronisation" vis-à-vis the gravity force towards the Chinese giant: when we listen, among the sobbing celebrities, to Maggie Cheung thanking "her mother", we might think she is actually referring to England. A gesture of reconnaissance of the (relative) freedom the ancient coloniser granted to the apolitical development of the arts?

I mentioned before Andy Lau: in his acceptance speech, extensively shown in The Moment, Lau links Taiwan and Hong Kong film production in a gesture of pan Asian, sinophone reconnaissance that binds the two cultures. They both have to struggle against the-one-who-must-not-be-named enemy, and they have already demonstrated that they can count on each other like knight errant, fighting for justice and freedom from the margins (this is mine interpretation, not Lau's words), ready to help each other in dire straits (as is the case, Lau's states, of Hong Kong film culture at the turn of the millennium). Andy Lau, objectified in Our Times and here spokesperson of a "sinophone" cinema, tells of a possible, yet only hinted, struggle with the continent. The Moment after all is a State Production, made for the celebration of the 50s anniversary of the once highly political and patriotic film festival... as reminded in the beginning of the film, the name Jin-ma stands for Jinmen and Mazu Islands, site of battles against the "communist bandits", and the ceremony was held the birthday of President Jiang.

What these texts stress is not a specific, original, ground-breaking style born on the Island (in the mood of Tsai Ming-liang), but the concrete everyday experiences of individuals as recreated in retro films, including the one that is used as a Proustian madeleine a string of sequences of classic movies. Propaganda films are not a specificity of Taiwan; but war films made in the 70s, celebrating the Nationalist Party victory over Japan during WW2, in reaction to the contemporary diplomatic setbacks, indeed are. And 2010s movies putting these classics in today's context are as well, because they create an interface between two generations who lived completely different ways of life and conceptions of politics.

\section{Looking back and forward at the same time}

Coercive force towards future battles, or anachronistic consolatory inward gaze? Drive to a healthy and proud museification and celebration of the too easily forgotten past, or dangerous mummification of creative forces? These multiple and contradictory readings of the retro trend are part of its charm. Often ridden with emotional overtones, celebration rhetoric, and nationalistic pathos, its very fabric can conceal anxieties about the present era and question the legitimacy of official celebration (The Moment: state funded), or of autobiographical nostalgia (Our Times). The texts discussed here, as their predecessors, display different combinatory strategy of representation of the past. The very multiplicity of these combinations appears urgent and relevant in present day search for roots and definition of collective identity. The importance of this artistic, popular historiography is evident: it can take the form of narration based on personal memories, or the multilayer metafilmic documentary recollection of archive images. They present complementary histories adding emotionally charged structures of feelings to the official history book narration and to the formal experiments of globally celebrated New Cinema. They all evaluate personal experience 
and all imply the multiplication of point of view and the legitimacy of contrasting interpretations. In the sense of Robert Rosenstone, who's developing the reflexions of Marc Ferro and Pierre Sorlin, these texts are legitimate forms of historiography, since they provide a "signification" of the past, and historical metaphors that can help the present to "think historically". ${ }^{16}$

The sweet, widespread images of nostalgia in Our Times, the geopolitical reconstructions of cinephilia of The Moment are historiographical visual metaphors. In the first, the public can feel a form of continuity with the immediate gone past, that is still lingering in the present: the iconic photos and paraphernalia of Andy Lau become literally alive when the actor in his own role appears in front of the astonished protagonist: a fragment of her youth is incarnated in front of her eyes (as a lost youthful spirit?). In The Moment, images of the past (sequences of classic films) are shown to contemporary audience (quite literally in the sequence of the ancient soldiers re-watching Victory) and thus interfaced with the contemporary gaze, both of the public who used to love the film back then, and of the present-day public who tries to make sense of its relevance. These metaphors engage contemporary thought in a continual reconfiguration of identities policies, where past is systematically brought back to life as a memento; or maybe and more accurately, the past is shown has having never left, and the very gesture of recognizing it can be the foundation and the drive to future reassessment of national identity. 


\section{Notes}

${ }^{1}$ Xiao Zhuang, 80 niandai shijianbu/80s Diary in Taiwan, Taibei, Daci, 2013.

${ }^{2}$ Huang Shengwen, Those Years Nage niao niandai, Taipei, Shangzhou, 2016.

${ }^{3}$ Wu Ming-yi Tianqiao shang de moshushi/The Illusionist on Skywalk and other short stories, Taipei, Xiari, 2011

${ }^{4}$ Corrado Neri, Retro Taiwan, Le temps retrouvé dans le cinéma sinophone contemporain, Paris, L'Asiathèque, 2016

${ }^{5}$ Robert Rosentstone, History on Film, Film on History: History: Concepts, Theories and Practice, Harlow, Pearson, 2006.

${ }^{6}$ The word 'retro' has a quite specific meaning: it refers to a self-conscious fetish for period stylization (in music, clothes, and design) expressed creatively through pastiche and citation. Retro in its strict sense tends to be the preserve of aesthetes, connoisseurs and collectors, people who possess a near-scholarly depth of knowledge combined with a sharp sense of irony. But the word has come to be used in a much more vague way to describe pretty much anything that relates to the relatively recent past of popular culture (Simon Reynolds, Retromania: Pop Culture Addiction to its own Past, London, Faber \& Faber, 2011, P. xii).

${ }^{7}$ Reynolds talks about a "vague" meaning; Guffey prefers to define it "imprecise": "Retro carries a pervasive, if somewhat imprecise, meaning; gradually creeping into daily usage over the past thirty years, there have been few attempts to define it. Used to describe cultural predisposition and personal taste, technological obsolescence and mid-century style (...) 'retro' can serve as little more than a trendy synonym for 'old-fashioned' or simply 'old'. (...) Retro can also describe an outlook on life. It may suggest a predisposition or inherent social conservatism that cleaves to the values and mores of the past (...) More than a quest for a simpler life, this 'retro' attitude also carries a darker suspicion that recent social, cultural and political developments are profoundly corrosive" (p. 9-10); Retro offers an interpretation of history that taps nostalgia and an undercurrent of ironic understanding. Steeped in satire and humour, retro's revivalist imaginary has made its way into the mainstream, shaping how recent past is presented in advertising, film, fashion and a host of form of popular culture (Elizabeth Guffey, Retro: the Culture of Revival, London, Reaktion Books, 2006, p. 27; italics mine).

${ }^{8}$ Hartmut Rosa and William Scheuerman (dir.), High Speed Society: Social Acceleration, Power and Modernity, University Park, Pennsylvania, Pennsylvania University Press, 2009.

${ }^{9}$ I obviously refer to the seminal definition by Benedict Anderson in Imagined Communities: Reflections on the Origin and Spread of Nationalism, London, Verso, 1991.

${ }^{10}$ Douwe Draaisma, The Nostalgia Factory: Memory, Time and Ageing, New Haven, Yale University Press, 2013.

${ }^{11}$ Alison Landsberg, Prosthetic Memory: the Transformation of American Remembrance in the Age of Mass Culture, New York: Columbia University Press, 2004.

${ }^{12}$ Wang Nianying Wu wang wo, zhenxin. Zhuangfan "Wode xiaonu shidai" daoyan Chen Yushan/Don't forget about me, sincerely. Interview with Our Times' director Chen Yushan, in Funscreen 520, 08-15-2015 : http://www. funscreen.com.tw/headline.asp?H_No=578 (accessed 09-07-18).

${ }^{13}$ Marc Ferro, Cinéma et Histoire, Paris, Gallimard, 1993, p. 23 (original edition 1977).

${ }^{14}$ Wang Gengyu Guangyin zhi lu. Taiwan xin dianying zai lushang/Film in our Time, Taibei, Beishi wenhuaju, 2015.

${ }^{15}$ Yang Lizhou Women de nashi nake. Huayu dianying wushi niandai liujinsuiyue/The Moment: 50 years of Sinophone cinema, Taibei, 30zazhi, 2016.

${ }^{16}$ You may also see these films as part of a separate realm of representation and discourse, one not meant to provide literal truths about past (as if our written history can provide literal truths) but metaphoric truths which work, to a large degree, as a kind of commentary on, and challenge to, traditional historical discourse (Rosenstone, 2006, pp. 8-9). 